\title{
Representações familiares nos anos iniciais do ensino fundamental: desenhos, genealogias e heredogramas
}

Rosemar de Fátima Vestena rosemarvestena@gmail.com 000-002-3785-0645 Franciscano, Santa Maria, Rio Grande do Sul, Brasil.

Elgion Lúcio da Silva Loreto elgionl@gmail.com

0000-0002-7586-8168

Universidade Federal de Santa Maria, Santa Maria, Rio Grande do Sul, Brasil.

\section{RESUMO}

Este artigo apresenta os resultados de uma pesquisa que objetivou analisar as três formas de representações da própria família do estudante trabalhadas nas escolas nos anos iniciais do ensino fundamental: desenhos livres, árvores genealógicas e heredogramas e verificar tanto as implicações relacionadas ao modo de estruturar a família quanto à inclusão e progresso dos conceitos científicos das Ciências da Natureza. A pesquisa é de abordagem qualitativa. Após revisão bibliográfica sobre os diversos tipos de representações familiares, buscaram-se exemplos dessas nos trabalhos fetos pelos estudantes nas séries iniciais. Constatou-se que as representações por meio de desenhos e genealogias pouco se apropriam dos conceitos científicos da área das Ciências da Natureza apesar do potencial das mesmas para acessar e catalisar estágios progressivos dos conhecimentos na área. Quanto às representações familiares por meio de heredogramas percebeu-se que estão bem próximas aos padrões científicos e tem grande potencial de ser trabalhado nesta etapa escolar.

Palavras-chave: Representações familiares. Anos iniciais. Ciências da Natureza. 


\section{Introdução}

No exercício da docência, percebe-se que as aulas de Ciências nos anos iniciais, em geral, além de raras, muitas vezes se efetivam por meio de atividades pontuais, com elaboração de painéis e informações sobre hábitos de higiene, partes das plantas, reinos dos seres vivos e datas comemorativas. Nossa observação encontra suporte em pesquisas como de Lorenzetti (2000) e Zanon e Freitas (2007). Estes estudos apontam, também, para a importância do ensino de Ciências já nesta fase escolar.

Aprender ciências significa ler e interpretar os fenômenos da natureza por meio do aprimoramento da capacidade de observar, experimentar, testar, representar, comunicar, controlar situações, montar, desmontar, construir, desconstruir tanto manualmente quanto mentalmente (PORTO RAMOS; GOULART, 2009; SANTOS, 2012).

Coutinho e Moreira (2001) destacam que, para Vigotsky, os conceitos científicos são aqueles que se organizam dentro de uma lógica legitimada socialmente, pelo fato de possuírem coerência interna e graus crescentes de generalizações. São geralmente adquiridos por meio do ensino. Os conceitos espontâneos são aqueles construídos informalmente no dia a dia, pelas relações sociais e atividades práticas das crianças. Vigotsky (1994) explica a existência de funções mentais que existem no estudante e que ainda não amadureceram, denominadas zona de desenvolvimento proximal. Necessitam análise prospectiva e, por isso, podem ser potencializadas por meio da mediação do professor e pelos seus recursos educacionais. Chama atenção também que a relação pedagógica formal é um dos principais caminhos para "puxar" o desenvolvimento, visto que é uma das principais fontes de conceitos científicos (COUTINHO; MOREIRA, 2001).

Krasilchik e Marandino (2010), explicam que a linguagem científica precisa ser estudada e decodificada para a melhor compreensão, pois a educação formal continua sendo um dos principais trajetos de acesso a estes saberes. Ensinar ciências nos primeiros anos escolares nem sempre foi uma prática considerada nas escolas. "Algumas correntes defendiam a posição em que a iniciação ao conhecimento científico, devido a sua complexidade, seria inacessível a compreensão das crianças. Tal afirmação parecia não só desconhecer as características psicológicas do pensamento infantil como desvalorizava a criança como sujeito social" (PORTO; PORTO, 2012, p. 29).

Segundo Krasilchic e Marandino (2010) a escola é tida como espaço de relação pedagógica formal onde se pode efetivar a alfabetização científica que, com o passar dos anos escolares, deveria ir progredindo em estágios cada vez mais abrangentes, permitindo aos cidadãos a leitura, interpretação e intervenção cidadã e responsável na realidade. Numa sociedade em que se convive com a supervalorização da tecnologia, não é possível pensar na formação de um cidadão crítico sem o saber científico (BRASIL, 1997). Para Salles e Kovaliczn (2007), a alfabetização científica se processa quando o estudante consegue descrever os fenômenos da natureza, por meio de uma linguagem científica, transpondo o senso comum para um saber sistematizado pela comunidade científica.

Por outro lado, nesta etapa escolar, o professor precisa se valer das 
saudável e sejam devidamente estimuladas por meio de recursos lúdicos, como brincadeiras, jogos, contos, desenhos, analogias, etc. (DINELLO 1998; FORTUNA, 2001).

Rego (2009) sinaliza que para Vigotsky as atividades lúdicas como as brincadeiras, desenhos, jogos, dentre outros possibilitam a expressão da criatividade o que a criança viu e sentiu, constituindo-se em "zonas de desenvolvimento proximal" que expressam os conceitos e subsidiam o seu processo de desenvolvimento.

Segundo Dinello (1998, p. 15), "quando se experimenta com materiais, se põem em funcionamento habilidades de procedimentos que se acompanham com descobrimentos conceituais". Santos (2012) destaca que o caráter lúdico de uma atividade pode funcionar como elemento motivador e facilitador da aprendizagem. Isso vem ao encontro das ideias defendidas por Vigotsky, já que o conceito de motivação permeia sua abordagem e se relaciona aos interesses, necessidades e vontades das crianças (REGO, 2009).

Conforme descreve Maranhão (2003), quando a criança faz o que gosta, o fato de aprender está unido ao prazer. Quanto ao conhecimento, é importante fazer corresponder os conteúdos científicos aos conhecimentos gerais das crianças, aos seus interesses e as suas necessidades, além de desafiar sua inteligência. Também o professor, ao organizar uma atividade lúdica, precisa do embasamento teórico do tema para poder planejar as etapas subsequentes, avaliando e comparando o que foi ensinado com o que foi aprendido e o que ainda necessita ser apresentado ou reforçado aos escolares (FRIEDMANN, 2006).

Lowelfeld (1977) e Laverberg (2006) destacam que as crianças, desde os primeiros anos escolares, mesmo antes de serem alfabetizadas, tem o desenho livre ou orientado como uma de suas principais formas de brincar, falar e questionar.

A expressão, na forma de desenho, lembra os primórdios da humanidade com suas pinturas rupestres. Para Ainsworth; Prain; Tytler (2011), também remetem aos primeiros registros das ciências, feitos especialmente em Botânica, Zoologia, Física, Química, etc. Portanto, na história da humanidade e das ciências, a observação, o registro e, por vezes, o hábito de tornar expresso, sob forma de desenhos e esquemas o que se está vendo, vivendo e pensando, caracterizam a humanidade, a ciência e a pesquisa. Para os autores, os desenhos e as representações gráficas se constituem como elemento chave na educação científica, uma vez que oferecem aos estudantes distintas formas de racionalidade e também atendem às diferenças individuais.

Entende-se por representação uma forma de expressão. Vergnaud (1991) apud Pretto (2012) apresenta alguns sentidos para representação, dentre eles o semiótico, considerando-a como um sistema de significados em que os significantes, representados pelos significados são necessariamente de ordem conceitual ou cognitiva e não de ordem material real.

Nos primeiros anos escolares, é comum os docentes solicitarem às crianças para que indiquem, nomeiem ou desenhem sua família. Por vezes, os familiares estão expostos em árvores da família ou árvores genealógicas, nas quais geralmente desenham ou são convidadas a completarem os dados na estrutura de 
uma 'árvore' fornecida pelo professor. "Assim, o ensino de ciências estará integrando mundo, pensamento e linguagem e possibilitando às crianças uma leitura de mundo mais consciente e ampla, ao mesmo tempo em que auxilia numa efetiva alfabetização dos alunos" (MORAES, 1995, p. 14).

As atividades, para construir árvores genealógicas, podem expressar a recuperação das origens de uma pessoa ou de uma família e podem ganhar múltiplos significados, tanto no plano simbólico, como na representação da vida.

Em algumas propostas didáticas, a representação da família é utilizada para se trabalhar a identidade da criança. Uma das temáticas mais frequentes são o estudo da organização da sociedade e seus elementos como a família, a escola e o bairro. Em um país formado por grande número de imigrantes, como o Brasil, esse interesse é muito pertinente, já que as procedências, que constituem a população brasileira, são muito diversificadas (ZAKZUK, 2007).

Segundo Dullius (2004), existem registros de que as árvores genealógicas foram representadas desde o Antigo Testamento, no formato patrilineares. Mas, a representação gráfica inicia-se durante a Idade Média, com formatos diferentes. O formato da árvore de Jessé $\left({ }^{* 1}\right)$ pode ter sido a primeira representação, a comparação com uma árvore propriamente dita. Para o pesquisador, têm-se duas formas de representar as árvores genealógicas; a primeira, como árvore de geração, também chamada de descendentes, pois parte das gerações mais antigas, chegando às mais jovens que pode ser representada como na Figura $1 \mathrm{~A}$ com a denominação de árvore da família e a segunda, árvore de costado, também chamada de ascendente, já que parte das gerações recentes e ascende às gerações mais antigas que pode ser representada como na Figura $1 \mathrm{~B}$.

Figura 1: Representações de árvores genealógicas. A) Árvore genealógica de descendência em que os ancestrais ficam representados no troco da árvore e os descendentes nos ramos; B) árvore genealógica de ascendência em que os ancestrais são representados nos ramos da árvore e o indivíduo representado é o tronco.

A
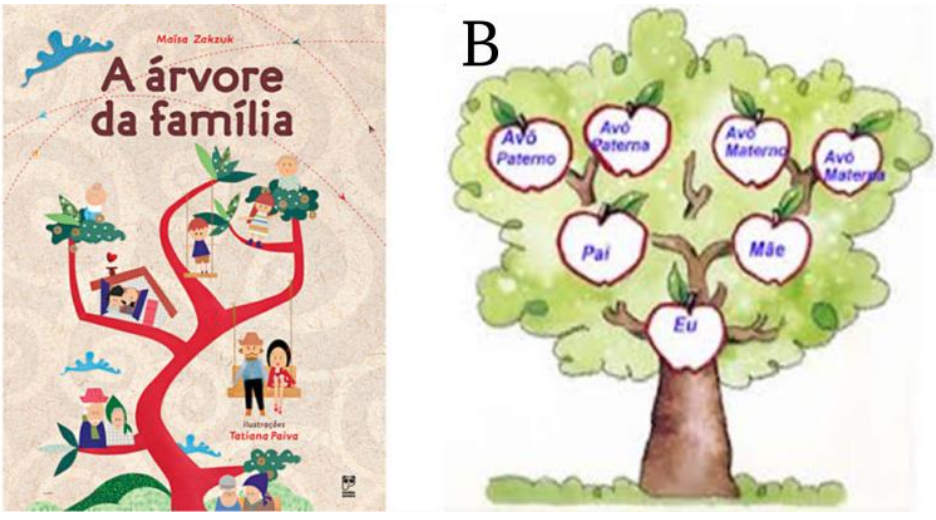

(Fonte: (A) Zakzuk (2007) e (B) http://educador.brasilescola.com/estrategias-ensino) 
As propostas de árvores se constituem em uma analogia com a morfologia de árvores no sentido botânico. Uma árvore geralmente é o resultado da reprodução sexuada das plantas e ocorre por meio das sementes que, ao germinarem, perpetuam a espécie. "Uma semente, trazida pelo vento, pousa sobre o solo e lá fica até as primeiras chuvas. Ao germinar, suas raízes começam a se desenvolver, e logo surge o primeiro ramo, e outro a partir deste, e mais outro, até o vicejar de uma árvore, com muitos galhos e folhas" (TOFOLI, 2008, p. 1).

Segundo Marcelos e Nagem, (2008) e Andrade, et al., (2014), a linguagem, por meio de analogia, é muito frequente como recurso para ensinar determinados conteúdos, auxiliando os alunos no processo de cognição de um conceito. Porém, Bachelard (1996) alerta que uma analogia pode vir associada a conhecimentos subjetivos, ligados aos conceitos prévios dos estudantes e que, por sua vez, podem dificultar o processo de aquisição do conceito objetivo em estudo. Dessa forma, pode servir de "obstáculo epistemológico" para a progressão do conhecimento. Pesquisas indicam o uso inadequado desses recursos, que derivam da escassa avaliação da eficácia das analogias empregadas na aprendizagem dos alunos (MARCELOS; NAGEM, 2008).

Outra forma de representar o pedigree de uma família se dá por meio de um heredograma que, geralmente, é proposto no ensino médio para trabalhar conceitos da hereditariedade.

A Figura 2 demonstra o Heredograma de uma família. Cada geração é representada em uma linha identificada por números romanos. Os indivíduos do sexo feminino são representados por círculos e os masculinos, por quadrados.

Figura 2: Estrutura do heredograma de uma família.

I.

II.
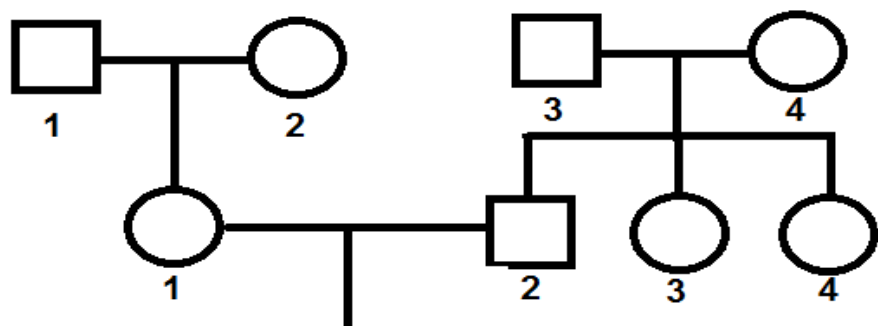

III.

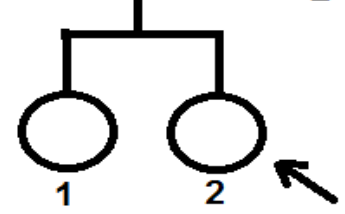

Fonte: Vestena; Sepel e Loreto (2015) 
Os heredogramas têm conotação voltada aos aspectos biológicos e médicos de uma família e utilizam-se de símbolos com padronização internacional. Segundo Banett et al., (2008), desde 1995, Pedigree Standardization Task Force (PSTF) e da National Society of Genetic Counselors (NSGC) apresentaram uma padronização internacional do sistema de nomenclatura dos heredogramas. Esses autores destacam que as referências de nomenclatura e símbolos necessitam ser reforçados na educação em Genética, na pesquisa Genética, na publicação científica, na documentação familiar e registros médicos.

Diante do exposto, este artigo objetiva analisar as três formas de representações da própria família do estudante, trabalhadas nas escolas nos anos iniciais do ensino fundamental: desenhos livres, árvores genealógicas e heredogramas e verificar tanto as implicações relacionadas ao modo de estruturar a família quanto à inclusão e progresso dos conceitos científicos da área das Ciências da Natureza.

\section{Metodologia}

A pesquisa é de abordagem qualitativa e priorizou-se analisar três tipos de atividades didáticas para representar a própria família dos estudantes dos anos iniciais do ensino fundamental: desenhos livres, árvores genealógicas e heredogramas. Tomando-se estas três categorias buscaram-se exemplos para cada tipo de representação familiar e, posteriormente, discutiu-se cada uma delas. Portanto, as imagens de representações familiares apresentadas são apenas exemplos para ilustrar e mediar às discussões acerca do tema. Ainda, foram destacadas nos três tipos de representações de família, as potencialidades didáticas de aproximação ou não com os conceitos científicos da área das Ciências da Natureza.

\section{Análise e discussão dos dados}

Desenhos livres: é um recurso utilizado com frequência nas escolas, como mostra a Figura 3, especialmente nos dois primeiros anos escolares, pelo fato da criança encontrar-se em processo de alfabetização.

Nas atividades ilustradas na Figura 3 percebe-se que as crianças foram solicitadas a representarem suas famílias, observando a sua estrutura que, geralmente, compõem-se de pai, mãe e filhos, portanto duas gerações. 
Figura 3 - Desenhos livres de famílias feitos por estudantes de 7 anos (A); 9 anos (B e C). (Fontes: (A) cadernos 20 ano, 2010, (B) 3asérie, 2006 e (C) 4o ano,2012 )
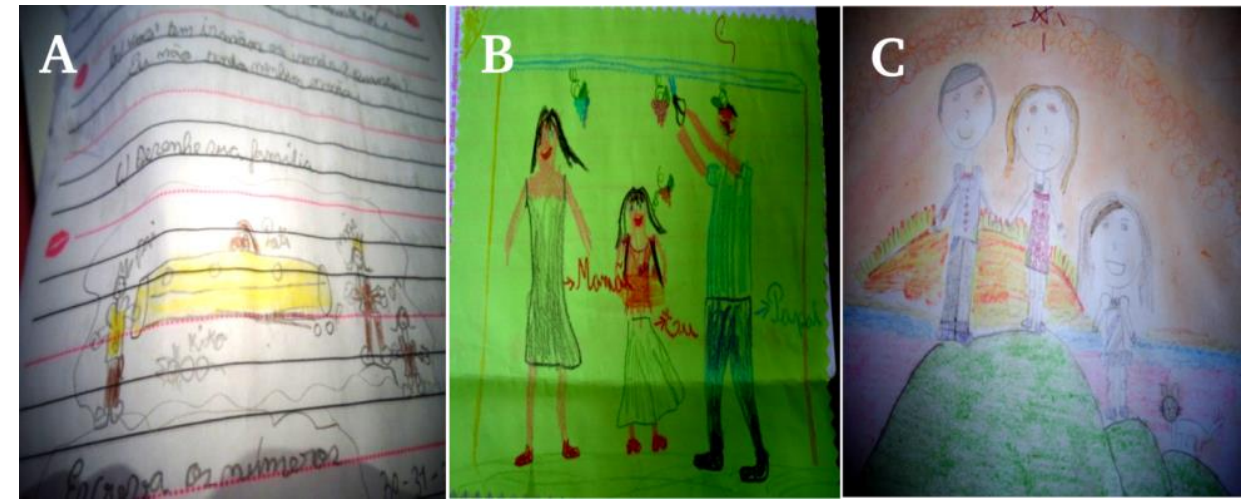

Os docentes, ao proporem desenhos livres, oportunizam às crianças a representação das particularidades de suas famílias, sem a interferência de materiais pré-elaborados. Também, é possível notar que não delimitaram o que deve aparecer nesses desenhos junto a sua família. Nessas atividades, há valorização da autoria da criança, permitindo uma experiência ímpar que, além de alfabetizar a criança para o desenho, instiga-a à observação, ao registro de informações e a formas de comunicar, reconhecer e aprender. Segundo Ainsworth, Prain e Tytler (2011), os desenhos oferecem aos estudantes distintos exercícios de racionalidade e também atendem às diferenças individuais. Em sala de aula, constituem-se em um recurso para superar os limites do material didático já editado, quando viabilizam a expressão das etapas de raciocínio dos estudantes, integrando novos conceitos aos já existentes.

As Figuras 3A e 3C são do mesmo estudante e ilustram a representação da sua família no segundo ano, quando tinha 7 anos, e no quarto ano, quando tinha 9 anos, respectivamente. Percebe-se que a proposta didática é praticamente a mesma, o que mudou foram as habilidades para o desenho do aluno, considerando sua idade. Entretanto, o uso desses recursos de forma indiscriminada e sem objetivos claros podem desperdiçar a oportunidade de se desenvolverem outras habilidades nas crianças, como a criticidade e resolução de problemas (DINELLO 1998; FORTUNA, 2001) ou de se trabalhar outros conceitos da área das ciências já que desde cedo as crianças costumam se interessar por suas origens como o nascimento, a concepção, informações acerca da sua família, envolvendo o passado, o presente e as perspectivas de futuro (PORTO; PORTO, 2012).

Estudiosos, como Lowelfeld (1977) e Laverberg (2006), destacam que as crianças passam por níveis de acordo com a faixa etária. Entre os 4 e 6 anos, os desenhos apresentam riqueza de detalhes, com destaque ao uso de cores. Dos 7 aos 8 anos, os desenhos podem ganhar perspectivas com maiores noções de profundidade, distância, relação métrica e proporcionalidade.

A Figura 3B ilustra a representação familiar, elaborada por um estudante de terceira série (quarto ano), com 9 anos de idade de uma escola privada, não confessional, de Santa Maria, RS. A criança procurou representar uma cena familiar em que o pai, com uma tesoura, colhe uvas, enquanto ela, em companhia da mãe, observa. 
Na Figura 3C, além dos humanos, observa-se um animal próximo à criança que parece incluí-lo como um integrante da família. A presença de indivíduos de outras espécies, compondo o conjunto de uma família, é muito comum nessa etapa escolar. Isto parece ser um fenômeno social cada vez mais frequente na sociedade atual, uma vez que os animais são chamados de 'filhos' e os adultos denominamse 'pais' e 'mães'. Estudos já denominam estes 'novos arranjos familiares', como famílias multiespécies (KNEBEL, 2012).

Assim como as crianças conquistaram seu espaço junto à família no decorrer da Idade Média; nos dias de hoje os animais de estimação também vêm adquirindo seu espaço; espaço este que não é conquistado, mas sim dado a eles pelos seres humanos. Então, estes novos protótipos de formação familiar que mesclam a relação e o convívio entre humanos e animais tem se tornado cada vez mais presente em nossa sociedade (KNEBEL, 2012, p. 37).

Quanto à aproximação ou não aos conceitos científicos, a atividade proposta, ilustrada pela Figura 3, tem potencial, uma vez que poderiam incluir as Ciências, abrindo caminho para o acesso e ao progresso de outros conhecimentos da área. A estrutura familiar dos estudantes pode oportunizar o estudo de temas como reprodução, descendentes e ascendentes, características físicas, ciclo de vida, etc. Porto e Porto (2012), ao se referirem ao bloco temático orientado pelos PCN (BRASIL, 1997), Ser humano e saúde, sugerem alguns temas que, segundo elas, derivam em assuntos correlatos.

Reprodução e fases da vida no desenvolvimento humano. Semelhanças e diferenças aparentes entre o corpo humano e o corpo de outros animais. Semelhanças e diferenças entre meninos e meninas, crianças e adultos. Semelhanças e diferenças relacionadas à etnia e a cultura (PORTO; PORTO, 2012, p.36). Nesta perspectiva, o estudo do ser humano é abordado de forma integrada e envolvido com a história de vida do indivíduo.

As dificuldades dos docentes, em aproveitar uma proposição didática para trabalhar os conhecimentos de outras áreas, parecem esbarrar numa formação curricular disciplinar ou na segmentação do currículo por áreas que não se relacionam. Isso se contrapõe às orientações das (DCNEF), Brasil (2010), as quais sinalizam que, nessa etapa escolar, necessita-se trabalhar a integração dos conhecimentos das diferentes áreas de conhecimento, por meio da otimização das atividades propostas aos estudantes. Segundo Kindel (2012), os professores dos anos iniciais deveriam ter mais competência para articular as áreas, porque a princípio, não pensariam como os professores das áreas ou disciplinas específicas, que tendem a valorizar umas sobre as outras no currículo. Deste modo, tende-se minimizar o caráter prescritivo e de controle do currículo, uma vez que passa a ser visto como dinâmico e flexível (CARLAN; SEPEL; LORETO, 2013).

Os desenhos livres, representados pelas figuras, tornar-se-iam excelentes recursos para dar seguimento aos conhecimentos escolares. Isso é reforçado pela teoria cognitiva de Vigotsky (1994), visto que a zona de desenvolvimento proximal se caracteriza na capacidade intelectual da criança, conforme níveis cognitivos iniciados e não complementados, porém, com a ajuda do professor, poderiam progredir numa relação descendente.

Porto, Ramos e Goulart (2009, p. 24) defendem a ideia de que o currículo escolar precisa se estruturar para que "apresente um mesmo conceito em diferentes momentos e diferentes níveis de elaboração ao longo do processo de 
escolarização, para que o aluno possa aprofundar e ampliar sua visão sobre o mundo científico".

Árvores genealógicas: as genealogias expostas na Figura 4 demostram os trabalhos elaborados por crianças de duas escolas, pertencentes a estados brasileiros diferentes, uma de Santa Catarina (SC) e outra do Rio Grande do Sul (RS). A Figura 4A representa a atividade elaborada por um estudante do segundo ano, com 7 anos. A Figura 4B representa a atividade elaborada por uma criança do quarto ano, com 9 anos. A Figura 4C representa a atividade elaborada por uma criança do segundo ano, com 7 anos, de uma escola pública de Santa Maria, RS. Estas atividades permitem perceber a valorização e a frequência dessa proposta didática em diferentes anos escolares e em diferentes estados e realidades sociais.

Figura 4 - Árvores genealógicas de famílias encontradas nos materiais de estudantes.
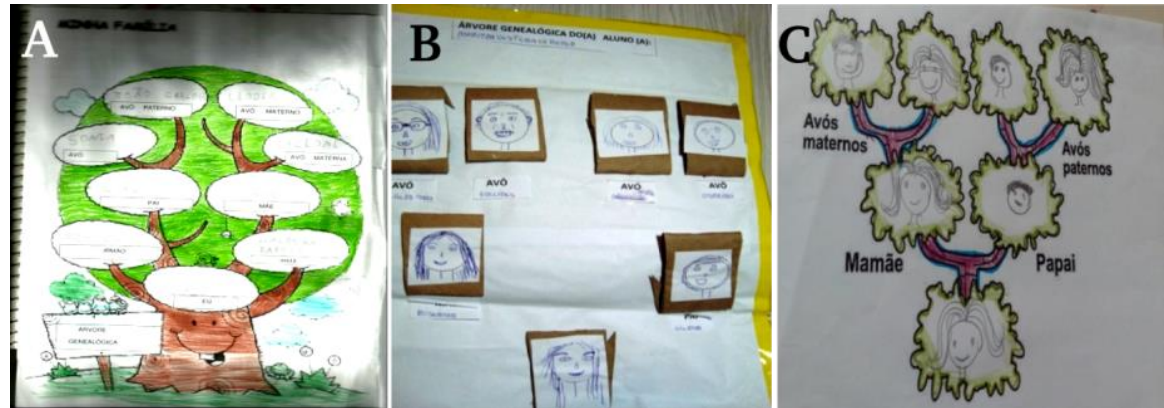

(Fonte: (A) de Itapema,SC, 2ㅇ ano, 2013; (B) Nova Palma, RS, 5ㅇ ano, 2011; (C) Santa Maria,RS, 2ㅇa, 2013)

A Figura 4A e 4B são denominadas árvores genealógicas. A Figura 4C não recebeu na atividade didática essa denominação, mas parece querer representar uma árvore, visto que os 'balões' lembram, tanto pela cor quanto pelo formato, o estereótipo de um ramo de árvore. A Figura 4A apresenta-se como um esboço de árvore como plano de fundo, e balões para que a criança complete os dados. $A$ Figura 4B lembra a estrutura de uma árvore e a Figura 4C parece representar os ramos de uma árvore.

Quanto às Figuras 4A e 4C, observa-se que são materiais didáticos impressos em que a criança apenas completa seus dados, escrevendo como na Figura 4A ou desenhando como na Figura 4C. Já Figura 4B demonstra uma atividade que foi confeccionada pelo estudante.

Nota-se que as três Figuras parecem representar uma árvore genealógica de ascendência (DULLIUS, 2004). Nestes três casos, os estudantes, que são as gerações mais novas, estão próximos aos troncos e as gerações mais antigas, nos ramos das 'árvores'. No entanto, essa analogia seria controversa uma vez que, para a Botânica, as partes mais jovens são os brotos que, por sua vez, estão nas extremidades. Assim, se os docentes tivessem proposto uma árvore genealógica de descendência, teríamos as gerações mais velhas compondo a base da árvore e as mais novas, o topo. Essa última proposta seria mais plausível aos estudantes para não gerar dúvidas quanto ao desenvolvimento das plantas. Porém, "não podemos deixar de considerar que metáforas e analogias são processos cognitivos culturais, lidam com conceitos e são passíveis de diversas interpretações" (ANDRADE, et al., 2014, p. 3). 
Outro aspecto com relação à estrutura é a possibilidade de se incluírem mais indivíduos da família nas genealogias dos estudantes, como tios e irmãos. Os desenhos da Figura 4 demonstram que foram oportunizadas as representações de três gerações, e a Figura 4A demonstra a possibilidade de incluir apenas 2 irmãos. Também, as atividades expostas nas Figuras 4B e 4C apresentam a possibilidade de se colocar apenas um filho que, no caso, é o próprio estudante, autor da genealogia.

Observa-se, na Figura 4A, que entre o pai e a mãe não existe o ramo que os ligaria como casais. Também não se consideram as idades dos irmãos. $O$ estudante estará na base da árvore independente se for o filho mais jovem ou mais velho. Quanto à Figura 4B, nenhum integrante da família que possui descendente apresenta-se ligado como casal. O que parece importar nessa atividade é a disposição na 'árvore' dos familiares que estão em ascendência em relação à criança (estudante). Para Andrade et al., (2014), as analogias servem como recursos cognitivos tanto para apresentar um conceito como para auxiliar o professor na explicação de um conceito. Porém, nem sempre desencadeiam o sucesso no aprendizado de um estudante e podem, inclusive, servir de obstáculo para progressivos conhecimentos. Elas devem ser recursos utilizados pelos professores para auxiliar a apresentação de conceitos.

A Figura 4C, ao representar três gerações, apresenta-se diferenciada das propostas 4A e 4B, porque os avós e os pais estão ligados como casais.

Os objetivos didáticos das atividades expostas na Figura 4B e 4C se diferenciam da atividade exposta na Figura 4A, porque apresentam uma maior participação dos estudantes e liberdade de expressão sob forma de desenho, além de pesquisarem os dados familiares. Segundo Ainsworth; Prain; Tytler (2011), os cientistas, por meio de representações visuais, como desenhos, diagramas, gráficos, fotografias, etc. criam novas relações entre os fatos e ideias, testam e elaboram conhecimentos, o que também se oportuniza, quando se dá liberdade de expressão aos estudantes.

Também, a atividade exposta na Figura 4A apresenta uma característica diferenciada das atividades expostas nas Figuras 4B e 4C, porque, no topo da árvore, estão os avôs paternos e maternos, logo abaixo as avós maternas e paternas. Descendo, nos ramos, o pai e a mãe, na sequência os irmãos e, por último, o aluno. Nessa situação, percebem-se também as questões de gênero estão no topo da árvore, os genitores do sexo masculino (avô paterno e materno). Isso pode expressar a visão androcêntrica, em que a valorização social do masculino é mais frequente na sociedade patriarcal, estendendo-se, inclusive, ao material didático (SOUZA; CAMARGO, 2011).

Com relação à aproximação ou não dos conceitos científicos, incluindo as Ciências, as representações da Figura 4 possuem potenciais de aproximação, visto que apresentam três gerações e, no caso da Figura $4 C$, união com traços entre os casais. As crianças podem perceber a ascendência de seus familiares, como também permite a reversibilidade, ou seja, perceberem a descendência com o passar das gerações.

Se considerarmos que as propostas didáticas pretendiam aliar a estrutura de uma árvore genealógica, tomando como base também a disposição das gerações de um heredograma que compõe uma amálgama dessas duas propostas, na Figura 4B estariam faltando as ligações entre os membros da família, os números dos 
indivíduos, das gerações e o emprego correto dos símbolos. Na Figura 4C, pelo fato de apresentar as ligações entre os membros compondo casais, estaria faltando o emprego dos símbolos. Assim, as potencialidades didáticas, com relação ao acesso aos conceitos científicos, são eminentes.

Heredogramas: Na Figura 5 temos representações de famílias na forma de heredogramas, oriundas de uma turma de estudantes do terceiro ano, de uma escola pública municipal de periferia, do município de Santa Maria, RS.

Figura 5 - Heredogramas de famílias feitos por estudantes.

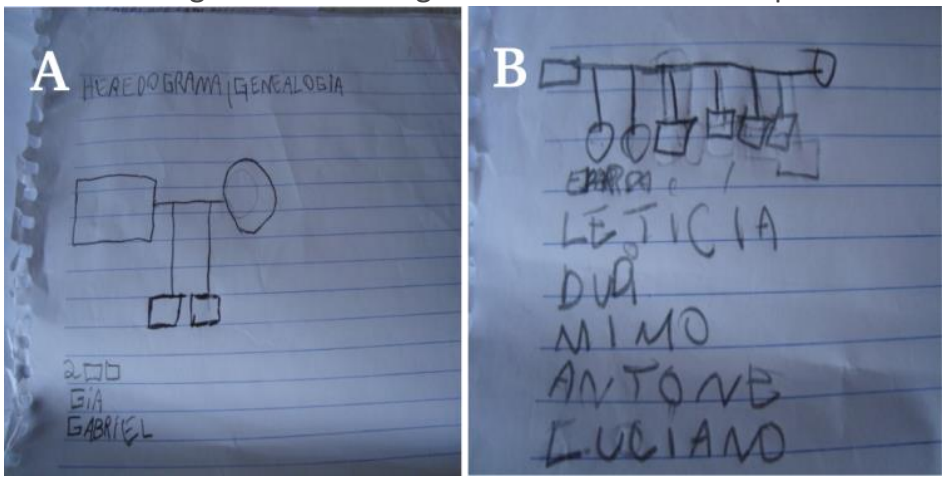

(Fonte: estudantes de $3^{\circ}$ ano de uma escola pública de Santa Maria, RS, 2013)

Observa-se que, apesar de se encontrarem no terceiro ano ainda, possuem dificuldades de se expressarem na escrita. Mal conseguem com letra bastão escreverem seus nomes e os de seus familiares. As Figuras foram categorizadas como heredogramas, uma vez que a Figura 5A apresenta o nome heredograma e genealogia grafados na borda superior da página. Nota-se que os dois termos são apresentados como sinônimos. Segundo Banett et al., (2008), seria conveniente apresentar para esta configuração apenas o termo heredograma, uma vez que, desde 1995, tem-se buscado uma padronização do sistema de nomenclatura e símbolos, para servirem como fonte de referência internacional.

Na Figura 5A, percebe-se a representação do pai, pelo símbolo do quadrado; da mãe, pelo símbolo do círculo e pelo traço horizontal, demarcando a união conjugal. Partindo dos traços verticais, a descendência de dois irmãos do sexo masculino é representada pelo símbolo quadrado. Na Figura 5B, tem-se a representação dos pais e de 6 irmãos, repetindo os símbolos e a configuração apresentada pela Figura 5A. Os traços da descendência partiram direto do traço que estabelece a ligação com os genitores. Na figura $5 \mathrm{~A}$ e $B$, temos também os nomes dos irmãos das crianças.

Apesar de todas as figuras representarem uma família dentro de um modelo tradicional (pai, mãe e filho), um heredograma oportuniza a possibilidade de novos arranjos familiares, ou seja, pais divorciados, uniões múltiplas (convivendo com mais de um cônjuge), etc.

Por outro lado, representar a família na atualidade pode ser um desafio, visto que, para Knebel (2012), as configurações familiares de hoje não são as mesmas de antigamente, apesar de esta última ter deixado resquícios para a família de hoje. Atualmente, tem-se um número maior de pais separados ou divorciados, avós cuidando dos netos com a autonomia de pais, famílias assumidas por um só adulto, indivíduos do mesmo sexo e suas crianças, etc. 
Quanto à aproximação ou não aos conceitos científicos, esta proposição didática é proximal, uma vez que, dentro desta faixa etária, as representações ficaram bastante satisfatórias, tomando como referência alguns conceitos científicos trabalhados. Para Vigotsky (1994), os conceitos científicos são aqueles que se organizam dentro de uma lógica legitimada socialmente, pela sua coerência interna e graus crescentes de generalizações. Vigotsky destaca que os conceitos científicos seriam o portal da consciência reflexiva das crianças (COUTINHO; MOREIRA, 1992). No entanto, maiores informações de como estruturar os heredogramas e outras simbologias podem ser encontradas no artigo de Vestena, Sepel e Loreto (2013). O que estaria faltando nos heredogramas, expostos na Figura 5, para se aproximarem ainda mais dos padrões científicos, seriam os números arábicos para indicar os indivíduos e os números romanos para indicar as gerações. Também observar que a descendência não parte direto da linha que une o casal. Porém, os problemas apresentados nos heredogramas podem ter sido uma opção ou falta de conhecimento do professor. Poderia não ter orientado devidamente os estudantes ou não ter priorizado o uso das informações faltantes nos heredogramas.

Para Vigotsky (1994), o ensino, por conta das disciplinas escolares, seria uma mediação semiótica por meio da linguagem e outros signos, em que os alunos estão expostos aos conhecimentos científicos cujos conteúdos são construções histórico-sociais da humanidade. Assim, na Figura 5, há signos escritos pelos números e palavras, mas também representadas pela estrutura gráfica. Observase que, apesar do precário nível de escolarização dos estudantes, quanto ao heredograma, eles se expressaram dentro do esperado, apesar das dificuldades. Isso demonstra que, para ensinar e aprender necessita-se organizar o conhecimento de formas variadas, atentando para as habilidades e progressivas oportunidades de crescimento conceitual dos alunos. Também, nessa etapa escolar pode-se propor o desenho da face do familiar dentro dos símbolos quadrados e círculos. Dessa forma se estaria propondo uma atividade lúdica que promove a observação, interpretação e uma forma simultânea de registro. A ludicidade facilita o desenvolvimento pessoal, social e cultural. Desenvolve a aprendizagem de habilidades de comunicação e expressão, socialização, construção de conceitos e novos conhecimentos (BRASIL, 1997, DINELLO, 1998; FORTUNA, 2001). Essas ideias convergem com a teoria de Vigotsky (1994) cuja mediação semiótica acontece na escola por meio da linguagem e de outros signos como os desenhos, que exercitam a capacidade de planejar, imaginar e representar o cotidiano.

\section{Considerações finais}

Após analisar as três formas de representações da própria família do estudante trabalhadas nas escolas nos anos iniciais do ensino fundamental: desenhos livres, árvores genealógicas e heredogramas e verificar tanto as implicações relacionadas ao modo de estruturar a família quanto à inclusão e progresso dos conceitos científicos da área das Ciências da Natureza, pode-se constatar que quanto aos desenhos, precisariam ser otimizados pelos docentes em uma proposta didática mais abrangente e integrada, atingindo os conceitos científicos. Quanto às árvores genealógicas, percebe-se que as analogias apresentam-se pouco viáveis para esta etapa escolar, porque geralmente são 
representadas como árvores genealógicas de ascendência. A comparação com árvores se apresenta como uma proposta controversa quanto a uma árvore de fato, o que pode gerar confusão para as crianças, tanto em relação aos conhecimentos de sua ascendência como indivíduo, quanto aos aspectos botânicos. Isso sinaliza que a busca por materiais e informações não teria passado pela interpretação crítica e criteriosa dos docentes antes de serem apresentadas aos estudantes.

Percebe-se que tanto os desenhos quanto as genealogias têm potencial para desencadear novos conhecimentos de forma gradativa, para acessar ou catalisar conhecimentos científicos, desde que os professores tenham o domínio do conhecimento, tanto da temática a ser ensinada quanto das correlações possíveis das serem feitas.

A representação na forma de heredograma pode ser incluída nos anos iniciais pelo seu potencial científico e pelo fato de existir uma padronização de estrutura e símbolos, aceitos internacionalmente.

O ensino dos conceitos envolvidos nas três representações familiares: desenhos, genealogias e heredogramas deveriam progredir em detalhes e informações científicas com o passar dos anos, para não se tornarem desinteressantes e repetitivas. Se esses recursos e conceitos forem incluídos e trabalhados desde a tenra idade, certamente poderão servir de substrato para a construção de conhecimentos nos anos subsequentes. Assim, no ensino médio, poder-se-ia avançar aprofundando outras questões da Genética.

Portanto, espera-se que esta pesquisa possa contribuir para a reflexão docente quanto ao processo de ensino e aprendizagem de conhecimentos científicos das Ciências, desde os primeiros anos escolares, e que, com o passar do tempo, sejam mais reconhecidos, acolhidos e estudados pelos estudantes da educação básica. 


\title{
Family representations in the early years of elementary school: drawings, genealogies and pedigree
}

\begin{abstract}
This article presents the results of a survey that aimed to analyze three different forms of the student's family representations, normally worked in schools in the early years of elementary school: free drawings, family trees and pedigrees and investigate the possibility of working scientific concepts, related to natural sciences, from these representations of families. The research is a qualitative approach. After literature review related to different types of family representations, we sought examples of those in student's notebooks. It was found that the representations through drawings and genealogies have a poor approaches to the scientific concepts in the field of natural sciences despite the potentia of them to access and catalyze progressive stages of knowledge in the area. The family's representations through pedigrees showed that are very close to scientific standards and has great potential to be worked in this school stage.
\end{abstract}

Keywords: Family representations. Early years. Natural Sciences. 


\section{Referências}

AINSWORTH, S.; PRAIN, V.; TYTLER, R. Drawingto Learn. Science Education, v. 333, n. 26, p. 1096-1097, 2011. Disponível em: http://product.design.umn. Acesso em: 28 fev. 2014.

ANDRADE, A. C. S. et al. Analogias e metáforas no ensino e aprendizagem do conceito de átomo: breve análise em livros didáticos. Scientia Plena, v. 10, n. 04, 2014. Disponível em: www.scientiaplena.org.br. Acesso em: 25 dez. 2014.

BACHELARD, G. A. Formação do espírito científico: contribuição para uma psicanálise do conhecimento. Rio de Janeiro: Contraponto, 1996.

BANETT, et al. Standardized human pedigree nomenclature: update and assessment of the recommendations of the National Society Genetic Counselores. Genetic Counselores, v. 17, 424-433. 2008. Disponível em: http://geneticcounselingtoolkit.com. Acesso em: 9 mar. 2014.

BRASIL. Secretaria de Educação Fundamental. Diretrizes Curriculares Nacionais para o Ensino Fundamental de 9 (nove) anos. Brasília: MEC/ SEF. 14 de dez. 2010. Disponível em: http://portal.mec.gov.br/. Acesso em: 10 mar. 2014.

Secretaria de Educação Fundamental. Parâmetros Curriculares Nacionais: Ciências Naturais/Secretaria de Educação Fundamental. Brasília: MEC/SEF, v. 4, 1997.

BRÖCKELMANN, R. H. Conexões com Biologia, v. 3. São Paulo: Moderna, 2013.

CARLAN, F. A.; SEPEL, M. N.; LORETO, E. L. S. Explorando Diferentes Recursos Didáticos no Ensino Fundamental: uma proposta para o ensino de célula. Acta Scientiae, v. 15 n. 2 p. 323-338 maio/ago. 2013. Disponível em: http://www.periodicos.ulbra.br/index. php/acta/article/view/265/675. Acesso em: 9 jan. 2015.

COUTINHO, M. T. da C; MOREIRA, M. Psicologia da educação: um estudo dos processos psicológicos de desenvolvimento e aprendizagem humanos, voltado para a educação. Belo Horizonte: Lê, 2001.

DINELLO, R. Pedagogia da expressão. Uberaba, MG: Universidade de Uberaba, 1998. 
FORTUNA, T. R. Formando professores na Universidade para brincar. In: SANTOS, S. M. P. (Org.). A ludicidade como ciência. Petrópolis, Rio de Janeiro: Vozes, 2001.

FRIEDMANN, A. O desenvolvimento da criança através do brincar. São Paulo: Moderna, 2006.

KINDEL, E. A. I. Práticas pedagógicas em Ciências: Espaço, tempo e corporeidade. Erechim, RS: Edelbra, 2012.

KNEBEL, A. G. Novas configurações familiares: é possível falar de constituição familiar desde a relação multiespécie? Monografia. UNIJUÍ, Ijuí, RS, 2012.

KRASILCHIK, M.; MARANDINO, M. Ensino de ciências e cidadania. São Paulo: Moderna, 2010.

LAVELBERG, R. O desenho cultivado da criança: Prática e formação de educadores. Porto Alegre: Zouk, 2006.

LOWENFELD, V. A criança e sua arte. São Paulo: Mestre Jou, 1977.

LORENZETTI, L. Alfabetização científica no contexto das séries iniciais. Dissertação de mestrado, Univ. Federal de Santa Catarina, Florianópolis, 2000.

MARANHÃO, D. Ensinar brincando. Rio de Janeiro: Nak, 2003.

MARCELOS, M. F.; NAGEM, R. L. Uso da analogia entra a árvore e a evolução por professores de Biologia. In: SEMINÁRIO NACIONAL DE EDUCAÇÃO PROFISSIONAL E TECNOLÓGICA. Atas. Centro de Educação Profissional Federal de Minas Gerais. Minas Gerais, B H, 2008.

MORAES, R. Ciências para séries iniciais e alfabetização. 2. ed. Porto Alegre: Sagra, 1995.

PORTO, A.; RAMOS, S.; GOULART, L. Um olhar comprometido com o ensino de Ciências. Belo Horizonte: FAPI, 2009.

PORTO, L.; PORTO, A. Ensinar ciências da natureza por meio de projetos: anos iniciais do ensino fundamental. Belo Horizonte: Rona, 2012. 
PRETTO, V. Construction des Connaissances et Exclusion Sociale, Notion de Genre: Cotutelle entre le Brésil et la France. 1. ed. Sarrebruck: Presses Académiques Francophones - PAF, 2012.

REGO, T.C. Vigotsky: uma perspectiva histórico-cultural da educação. Petrópolis, RJ: Vozes, 2009.

SALLES, G; KOVALICZN, R. O mundo das Ciências no espaço da sala de aula: O ensino como um processo de aproximação. In: NADAL, B.G. (Org.). Práticas Pedagógicas nos anos iniciais: concepção e ação. Ponta Grossa: Vepg, 2007.

SANTOS, E. I. Ciências nos anos finais do ensino fundamental: produção de atividades em uma perspectiva sócio histórica. São Paulo: anzol, 2012.

SOUZA, N. G. S.; CAMARGO, T. S. O corpo no ensino de Ciências: serão possíveis outras abordagens? In: SILVA, F. F.; MELLO, M. B. Corpos, gêneros, sexualidades e relações étnico-raciais na educação. Uruguaiana, RS: UNIPAMPA, 2011.

TOFOLI, D. Entendendo a árvore da vida: conexões evolutivas. Genética na escola, v. 3, n. 2, p. 1, 2008. Disponível em: http://geneticanaescola.com.br/wp-home/wpcontent/uploads/2018/. Acesso em: 12 jan. 2015.

VESTENA, R. F. SEPEL, L. N.; LORETO, E. L. S. Heredogramas dos estudantes: das anágrafes paroquiais para a escola. Genética na Escola, v 8, n. 2, 2013, p.114-123. Disponível em: http://geneticanaescola.com.br/wp-home/wpcontent/uploads/2013/08/VersPress/. Acesso em: 9 jan. 2015.

VESTENA, R. F.; SEPEL, L. N.; LORETO, E. L. S. Construção do heredograma da própria família: uma proposta interdisciplinar e contextualizada para o ensino médio. Revista Electrónica de Enseñanza de las Ciencias, v. 14, n. 1, p. 1-118, 2015. Disponível em: http://reec.uvigo.es/volumenes/volumen14/REEC. Acesso em: 9 jan. 2015.

VYGOTSKY, L. S. A formação social da mente: o desenvolvimento dos processos psicológicos superiores. São Paulo: Martins Fontes, 1994.

ZAKZUK, M. A árvore da família. São Paulo: Panda Books, 2007.

ZANON, D.A.V.; Freitas, D. A aula de ciências nas séries iniciais do ensino fundamental: ações que favorecem a sua aprendizagem. Ciências \& Cognição, v. 10, p. 93-103, 2007. 
Recebido: 06 jan. 2016.

Aprovado: 07 dez. 2016.

DOI: 10.3895/rbect.v9n1.2940

Como citar: VESTENA, R. F.; LORETO, E. L. S. Representações familiares nos anos iniciais do ensino

fundamental: desenhos, genealogias e heredogramas. Revista Brasileira de Ensino de Ciência e

Tecnologia, v. 9, n. 3, 2016. Disponível em: <https://periodicos.utfpr.edu.br/rbect/article/view/2940>. Acesso

em: $x x x$.

Correspondência: rosemarvestena@gmail.com

Direito autoral: Este artigo está licenciado sob os termos da Licença Creative Commons-Atribuição 4.0 Internacional.

\section{(c) (1)}

